\title{
Study on Water Characteristic Curve and Shear Characteristics of Typical Unsaturated Silty Clay in Shaoxing
}

\author{
Ruiqian Wu $\mathbb{D}^{1}$, Youzhi Tang $\mathbb{D},{ }^{1}$ Shaohe Li $\mathbb{D}^{2}{ }^{2}$ Wei Wang $\mathbb{D},{ }^{1}$ Ping Jiang $\mathbb{D}$, \\ and Guang Yang iD 1 \\ ${ }^{1}$ School of Civil Engineering, Shaoxing University, Shaoxing 312000, China \\ ${ }^{2}$ School of Civil Engineering, Zhejiang Institute of Industrial Technology, Shaoxing 312000, China \\ Correspondence should be addressed to Wei Wang; wellswang@usx.edu.cn
}

Received 25 February 2021; Revised 6 May 2021; Accepted 16 June 2021; Published 9 July 2021

Academic Editor: Yi Xue

Copyright (C) 2021 Ruiqian Wu et al. This is an open access article distributed under the Creative Commons Attribution License, which permits unrestricted use, distribution, and reproduction in any medium, provided the original work is properly cited.

\begin{abstract}
In order to probe into one simplified method to predict the shear strength of Shaoxing unsaturated silty clay, the test method combining unsaturated soil consolidation instrument and conventional direct shear instrument is used to study the shear strength, and the method is compared and verified with the results of equal suction direct shear test. The research results show that the soil water characteristic curve fitted by the measured data points and VG model has obvious stage characteristics in the range of $0 \sim 38 \mathrm{kPa}, 38 \sim 910 \mathrm{kPa}$, and $910 \sim 10000 \mathrm{kPa}$. The shear strength of unsaturated soil measured by consolidation meter combined with conventional direct shear test is in good agreement with that measured by equal suction direct shear test in the range of $0 \sim 500 \mathrm{kPa}$. The results show that the shear strength, total cohesion, and effective internal friction angle of soil increase slightly with the increase of matric suction in the range of $0 \sim 38 \mathrm{kPa}$. When the matric suction increases from $38 \mathrm{kPa}$ to $500 \mathrm{kPa}$, the shear strength and total cohesion force of the soil have similar stage characteristics with the SWCC, which first increases and then tends to be stable, while the effective internal friction angle changes slightly. Finally, taking the air-entry value as the demarcation point, an improved model of unsaturated shear strength is proposed by analyzing the error value. Compared with the measured value, the absolute value of relative error is basically kept in the range of $5 \% \sim 10 \%$, which is close to the measured value.
\end{abstract}

\section{Introduction}

Unsaturated soils widely exist in nature, and their engineering properties are quite different from saturated soils. The soils above the groundwater level are generally considered as unsaturated soils. With the change of seasons and rainfall, the unsaturated state is constantly changing. The failure of foundation and slope occurs easily, and it brings great threat to the safety of buildings and structures [1,2]. Ciabatta et al. [3] have shown that a large amount of rainfall caused by changing global climate may cause more frequent slope failure. It has serious impact on the safety of human life and property. Rahardjo et al. [4] studied the residual soil slope, and they found that the high and steep residual soil slope could be safe in the dry period and only collapsed in the rainy season. The phenomena indicate that the stability of the slope is related to the additional shear strength of the unsaturated zone above the groundwater level. The infiltration of rainwater during rainfall affects the negative pressure of the pore water which decreases the additional shear strength of the unsaturated soils and leads to slope failure easily $[1,5-7]$.

In order to improve the properties of saturated and unsaturated soils, some scholars try to add inorganic cementitious materials such as cement into the soils $[8,9]$ or add cement, nano, fiber, and other mixed materials [10-12]. Obviously, in theory and in practice, it is very important to understand and investigate the characteristics especially the shear strength of unsaturated soils directly, which exist widely in nature. Mohr-Coulomb strength theory has been confirmed by a large number of tests and engineering practice. It can accurately determine the shear strength of saturated soil. However, at the beginning of the 20th century, the strength of unsaturated soil was similarly predicted by the Mohr-Coulomb shear strength formula for saturated soil. 
Until later, with the development of the mechanics of unsaturated soil, many scholars have done a lot of research on the relationship between the shear strength of unsaturated soil and matric suction [13-18]. Idinger and $\mathrm{Wu}$ [19] showed that the matric suction reduced the shrinkage effect of granular soil and increased the total cohesion, while the effective angle of internal friction did not change too much; Rasool and Kuwano [20] studied the influence of matric suction on the shear strength of unsaturated silty soil, and they found the relationship between matric suction and shear strength was nonlinear; Pujiastuti et al. [21] pointed out that the total cohesion and effective angle of internal friction of unsaturated sand will increase with the increase of matric suction, but the shear strength increase a little. Khalili et al. [22] studied the mechanical behavior of unsaturated soils and found that the total cohesion increased linearly within the range of high matric suction. Çokça and Tilgen [23] studied the relationship between the shear strength of Ankara compacted clay and matric suction and found that the matric suction and shear strength were correlated positively. Inevitably, Mohr-Coulomb shear strength formula will lead to errors when it is used to predict the shear strength of unsaturated soils.

In geotechnical engineering practice, permeability coefficient, shear strength, and other relevant indexes describing the behavior of unsaturated soils can be obtained indirectly by using the soil-water characteristic curves [24-30]. According to the influence of matric suction on the cohesion and internal friction angle of unsaturated soil, many scholars used the Mohr-Coulomb strength failure criterion of saturated soil and the measured shear strength parameters of saturated soil and soil-water characteristic curve to predict the shear strength of unsaturated soil. For example, Vanapalli et al. [31] proposed a nonlinear shear strength calculation model related to soil-water characteristic curve of soil mass. Oberg and Sallfors [32] presented a formula for calculating the shear strength of unsaturated soils in combination with soil saturation and matric suction. Tang et al. [33] discussed the feasibility of using conventional direct shear instrument combined with the initial soil-water characteristic curve of 0 pressure to estimate the strength of unsaturated soil.

This paper conducted three experiments, respectively, for the unsaturated soil consolidation test, conventional direct shear test, and equal suction direct shear test. The unsaturated soil consolidation test can obtain soil-water characteristic curve, which describes the relationship between matric suction and water content of soils and reflects the waterholding capacity of soils under suction [33]. The conventional direct shear test is to obtain the shear strength of the soil with different water contents, which reflects the relationship between the different water content and the shear strength; the equal suction direct shear test can directly obtain the shear strength of the soil under different matric suction states. It is difficult to measure the required test analysis data in a short time because of the time-consuming of the constant suction direct shear test. However, the unsaturated soil consolidation test combined with conventional direct shear test can achieve the same test purpose as the direct shear test with equal suction, and the time consumption is relatively short. In this paper, the influence of matric suction on the shear strength of soil is analyzed by combining the unsaturated soil consolidation test with the conventional direct shear test and by comparing and checking the partial equal suction direct shear test. At the same time, based on the soil-water characteristic curve fitted by VG model, the shear strength prediction values of three typical models are calculated, and the model is improved through error analysis.

\section{Test Materials and Preparation}

2.1. Test Materials. The test soil sample is taken from the bottom of a cutting foundation pit in Keqiao District, Shaoxing, and the basic physical property indexes of the test materials are shown in Table 1. It can be seen from the table that the particle size of the soil sample is mainly between $0.005 \mathrm{~mm}$ and $0.075 \mathrm{~mm}$, among which the average sand content is $21.43 \%$, the average silt content is $64.52 \%$, the clay content is $14.05 \%$, and plastic index is 12.5 , which is between 10 and 17. According to the code of Engineering Classification Standard of Soil (GB/T50145-2007) [34], it is judged to be low liquid limit silty clay.

2.2. Sample Preparation. In this experiment, remolded soil samples are dried, crushed, and sieved for $2 \mathrm{~mm}$, and then, the natural stacking quartering method is used for diagonal sampling. Through theoretical calculation, the required distilled water is evenly sprayed on the surface of remolded soil sample and fully mixed, and then, the soil sample is prepared into a loose shape, sealed in a moisture retaining plastic bag, and placed in a moisture container for more than $48 \mathrm{~h}$, so that the moisture in the soil can be fully transported and mixed evenly. According to the requirements for soil sample preparation in Standards for Geotechnical Test Methods [35], a disc-shaped sample with a diameter of $61.8 \mathrm{~mm}$ and a height of $20 \mathrm{~mm}$ is prepared by the layered compaction method with different dry density.

2.3. Test Scheme. The unsaturated soil consolidation instrument (SDSWCC) used in the test is made in Nanjing TKA company, and it is shown in Figure 1. According to the code of Technical specifications for highway subgrade construction [36], the compactness of urban secondary trunk roads is not less than $93 \%$, and branch roads are not less than $90 \%$. The water content is close to the optimal water content $\omega_{\text {op }}=$ $18.4 \%$. Therefore, this test selects the lowest compaction degree $(\mathrm{Dc}=0.90)$ of the silty clay of the cutting base. In various natural unsaturated soils, the matric suction range that affects the shear strength of the soil is usually $0 \sim 500 \mathrm{kPa}$ [17, 37-39]. Therefore, in this study, the matric suction range of the unsaturated soil consolidation test is taken as $0 \sim 500 \mathrm{kPa}$. The saturated sample is put into the unsaturated soil consolidation instrument, and apply the matric suction path of $1 \mathrm{kPa}, 25 \mathrm{kPa}, 50 \mathrm{kPa}, 75 \mathrm{kPa}, 100 \mathrm{kPa}$, $150 \mathrm{kPa}, 200 \mathrm{kPa}, 250 \mathrm{kPa}, 300 \mathrm{kPa}, 400 \mathrm{kPa}$, and $500 \mathrm{kPa}$ to the sample in sequence to dehydration test. The stability standards of deformation and drainage during the test are as follows: the vertical deformation and displacement do not exceed $0.01 \mathrm{~mm} / 2 \mathrm{~h}$ and $0.01 \mathrm{~cm}^{3} / 2 \mathrm{~h}$, respectively, and 


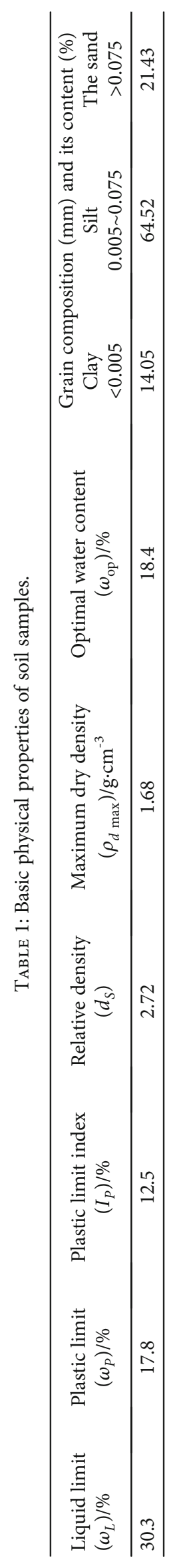




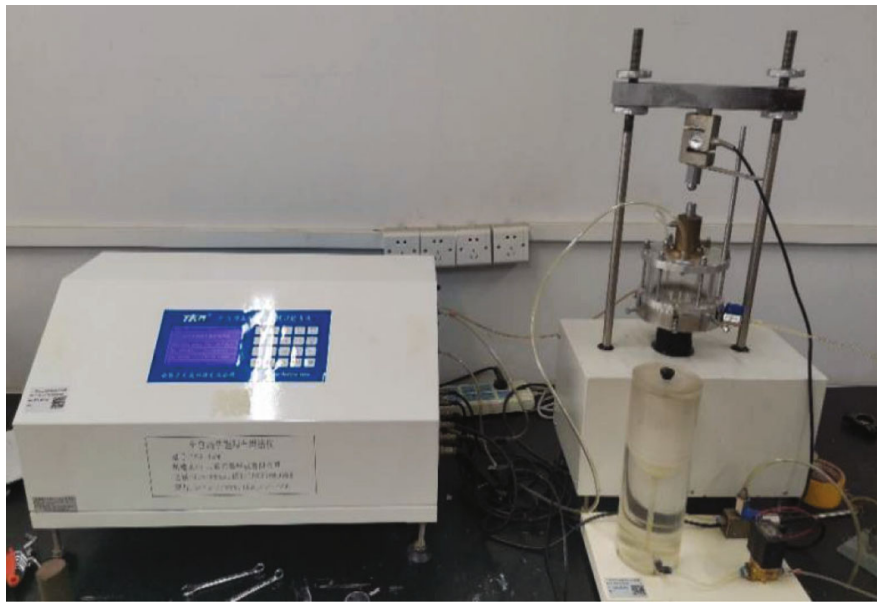

FIgURE 1: Unsaturated soil consolidation instrument.

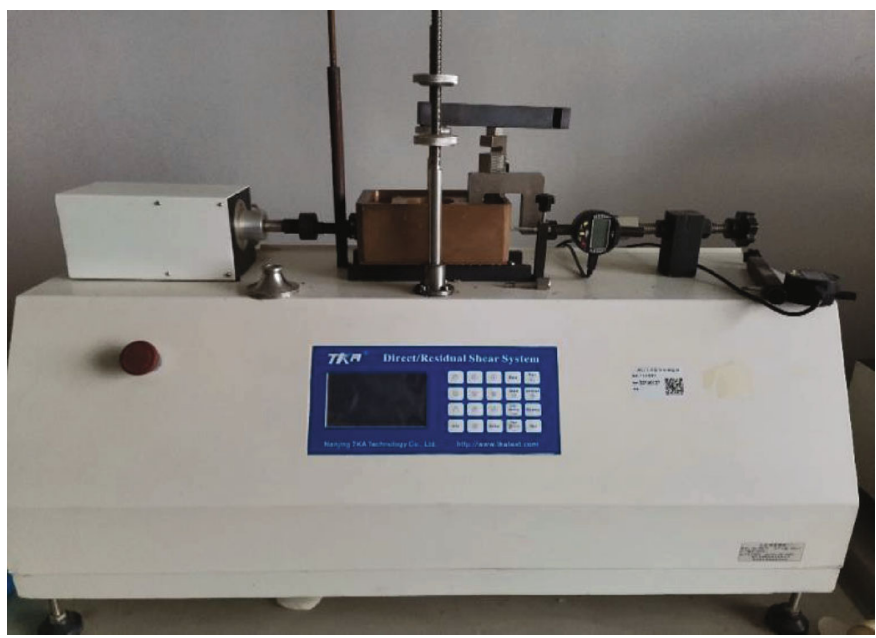

FIGURE 2: Fully automatic direct shear instrument.

the suction time of each stage is not less than $48 \mathrm{~h}$. In order to reduce the error of displacement calculation, the pipeline at the bottom of the ceramic plate is bubble washed every $1 \mathrm{~d}$ during the test, so as to eliminate the influence of the air at the bottom of the ceramic plate.

This test is $t$ unsaturated soil direct shear test with the same degree of compaction (Dc $=0.90, \rho_{d}=1.51 \mathrm{~g} \cdot \mathrm{cm}^{-3}$ ) under different water content of the test instrument is made from Nanjing TKA production of fully automatic saturated soil direct shear instrument, as shown in Figure 2. Based on the soil-water characteristic curve obtained in the above test (Figure 2), samples are taken according to the volume water content corresponding to the matric suction of $25 \mathrm{kPa}, 38 \mathrm{kPa}, 50 \mathrm{kPa}, 75 \mathrm{kPa}, 100 \mathrm{kPa}$, $150 \mathrm{kPa}, 200 \mathrm{kPa}, 300 \mathrm{kPa}, 400 \mathrm{kPa}$, and $500 \mathrm{kPa}$, and the volume water content corresponding to the suction path is $43.3 \%, 41.8 \%, 40.4 \%, 37.4 \%, 34.8 \%, 30.8 \%, 28.8 \%, 24.4 \%$, $22.3 \%$, and $20.9 \%$, respectively. Three samples of each water content are prepared, and vertical stress of 50,100, and $200 \mathrm{kPa}$ is imposed for the direct shear test. The shear rate in the test is $0.0032 \mathrm{~mm} / \mathrm{min}$. The water content is measured by the drying method. To ensure the water content retaining constant, an impermeable plastic film is placed between the permeable stone and the soil sample during the test to reduce water loss.

The equal suction direct shear test equipment is from unsaturated soil direct shear instrument produced by Nanjing TKA LTD., as shown in Figure 3, which uses the axis translation technology to realize the direct shear test of matric suction control for samples with different saturations. In order to carry out comparative study, the samples are prepared with the optimal water content of $18.4 \%$ and compactness of $0.90\left(\rho_{d}=1.51 \mathrm{~g} \cdot \mathrm{cm}^{-3}\right)$. The test consists of three stages, respectively, suction balance stage, equal suction consolidation stage, and equal suction shear stage. Combined with the regional characteristics of Shaoxing unsaturated silty clay, the matric suction is set at $0 \mathrm{kPa}, 25 \mathrm{kPa}, 50 \mathrm{kPa}$, $75 \mathrm{kPa}, 100 \mathrm{kPa}, 150 \mathrm{kPa}, 200 \mathrm{kPa}, 300 \mathrm{kPa}, 400 \mathrm{kPa}$, and $500 \mathrm{kPa}$, and the net vertical stress is $50 \mathrm{kPa}, 100 \mathrm{kPa}$, and $200 \mathrm{kPa}$, respectively. In order to adapt to the characteristics of homogeneous and slow dissipation of pore pressure and pore water pressure in unsaturated soil during direct 


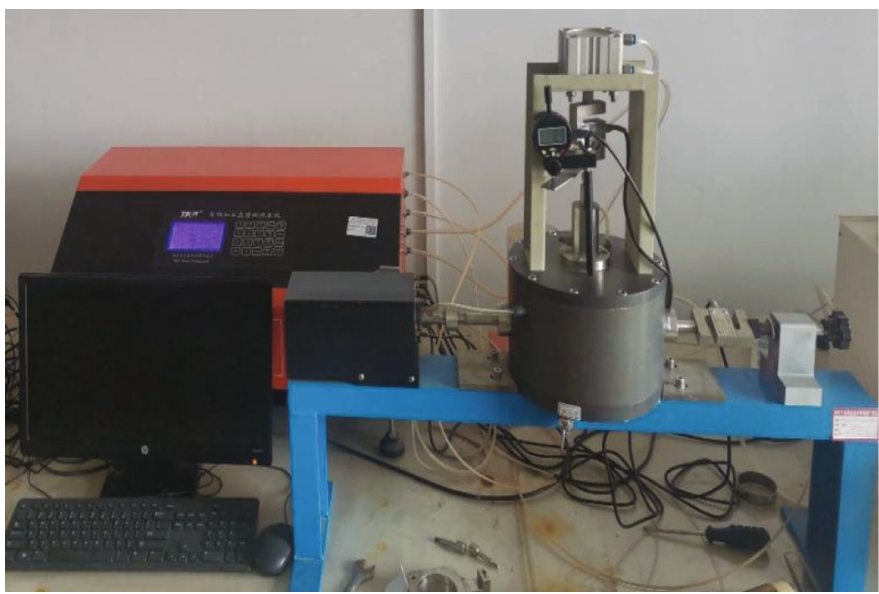

Figure 3: Unsaturated soil direct shear instrument.

TABLE 2: Corresponding values of matric suction and water content in unsaturated soil consolidation test.

\begin{tabular}{|c|c|c|c|c|c|c|c|c|c|c|}
\hline Matric suction/(kPa) & 1 & 25 & 50 & 75 & 100 & 150 & 200 & 300 & 400 & 500 \\
\hline Mass water content/(\%) & 29.7 & 28.8 & 27.8 & 24.9 & 22.1 & 20.5 & 19.0 & 16.8 & 15.0 & 13.4 \\
\hline Volume water content/(\%) & 44.9 & 43.5 & 42.0 & 37.6 & 33.4 & 31.0 & 28.7 & 25.4 & 22.7 & 20.2 \\
\hline
\end{tabular}

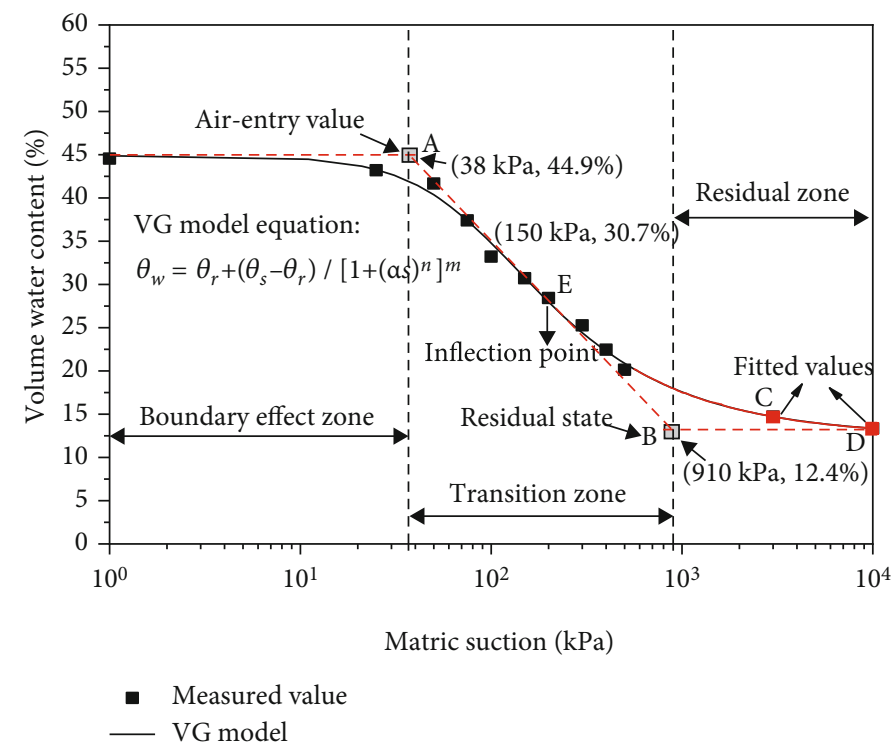

FiguRE 4: Fitting results of test data of soil-water characteristic curve.

shear test, the shear rate of the sample is $0.0032 \mathrm{~mm} / \mathrm{min}$ and the horizontal displacement is $6 \mathrm{~mm}$. After each sample is sheared, part of the soil is taken from the shear plane, and the water content after shearing is measured by drying method.

\section{Test Results and Analysis}

3.1. Unsaturated Soil Consolidation Test Results and Analysis. Under the action of different matric suction, the mass water content corresponding to the equilibrium and stable of the sample by the consolidation test of unsaturated soils is shown in Table 2. The measured mass water content is converted into the corresponding volume water content to establish the relationship between the volume water content and the matric suction, as shown in Figure 4. It can be seen that the volume water content shows a significant downward trend with the increase of matric suction. At the beginning, the volume water content drops slowly, then the curve steepens, and the rate of decline increases obviously. However, with the 
TABLE 3: Basic parameters of VG model.

\begin{tabular}{lcccccc}
\hline \multirow{2}{*}{ Model } & $\alpha$ & \multicolumn{3}{c}{ Fitting parameters } & $\theta_{r} / \%$ & Fitting correlation coefficient $R^{2}$ \\
\hline VG model & 0.0122 & 1.733 & 0.423 & 44.9 & 12.4 & 0.9949 \\
\hline
\end{tabular}

further increase of matric suction, the decreasing rate of moisture content in the sample volume gradually slows down.

Since most of the model equations describing the soilwater characteristic curve are based on experience and the shape of the curve, many scholars have proposed different model equations. The representative soil-water characteristic curve equations include Gardner equation [40], BrooksCorey model [41], Van Genuchten model [29], and Fredlund and Xing model [30]. Among them, the parameters of the Van Genuchten model have a dear physical meaning, and its fitting effect is perfect, so it is widely used in practice. Therefore, the curve between matric suction and volume water content of unsaturated silty clay in this paper is fitted with the Van Genutchen model, and its expression is as follows:

$$
\theta_{w}=\theta_{r}+\frac{\left(\theta_{s}-\theta_{r}\right)}{\left[1+|a s|^{n}\right]^{m}},
$$

where $\theta_{w}$ is the volumetric water content (\%); $\theta_{s}$ is the saturated volumetric water content; $\theta_{r}$ is the residual volumetric water content; $s$ is the matric suction $(\mathrm{kPa}) ; \alpha$ is the parameter related to the inlet value $\left(\mathrm{kPa}^{-1}\right) ; n$ is parameters related to the degree of drainage; $m$ is a parameter related to residual water content, where $m=1-1 / n$.

The logarithm of matric suction is made as abscissa, and volume water content is taken as ordinate, and VG model is used to fit the test data. The soil-water characteristic curve fitted by measured data points and VG model is shown in Figure 4. Among them, matric suction $0 \sim 500 \mathrm{kPa}$ is the measured value fitting range, and $500 \sim 10000 \mathrm{kPa}$ is the model prediction range. Basic parameters of the fitting are shown in Table 3. Among them, the parameters $\alpha, n, m, \theta_{s}$, and $\theta_{r}$ are obtained by inputting the VG model formula and the corresponding values of matric suction and water content measured in the experiment into Origin Software for fitting. As can be seen from Figure 4, the soil-water characteristic curve fitted by VG model shows an inverse "S" shape with obvious three stages. This result is similar to the law of dividing the soil-water characteristic curve dehydration process into three stages: boundary effect zone, transition zone, and unsaturated residual zone. The air-entry value of soil sample is $38 \mathrm{kPa}$, the residual volume water content is $12.4 \%$, and the matric suction corresponding to the turning point of soilwater characteristic curve is $150 \mathrm{kPa}$. Within the value of $500 \mathrm{kPa}$ matric suction, the soil-water characteristic curve fitted by the measured value shows obvious two-stage characteristics, which corresponding to the boundary area and transition area of the typical soil-water characteristic curve, respectively. In the boundary area $(s=0 \sim 38 \mathrm{kPa})$, the volume water content of soil did not decrease obviously with the increase of matric suction. This is because the initial water content of the sample is close to saturation, and the pore pressure is small which the gas in the soil can only be suspended in water in the form of closed bubbles and flow together with the water. At this time, the soil loses less water and is close to the saturated soil. When the matric suction increases to the air-entry value and reaches the transition zone $(38 \mathrm{kPa} \leq s \leq 910 \mathrm{kPa})$, the soil sample begins to lose water rapidly at a certain rate. This is due to the increase of pore pressure, and the water in the soil will be gradually discharged by gas and occupied a larger pore channel. With the further increase of pore pressure, more water will be discharged from the soil, and the soil water content will decrease rapidly. When the matric suction is in the unsaturated residual zone $(s \geq 910 \mathrm{kPa})$, and the pore pressure continues to increase and the water in the soil is little or no longer discharged, it is considered that the soil has reached the residual water content.

Compared with the typical soil water characteristic curve, due to the limitation of the test instrument, the maximum air intake value of the clay plate is $500 \mathrm{kPa}$, and the data corresponding to the residual zone cannot be measured by the instrument, so the residual area of the sample can only be predicted by fitting. At present, many definitions of residual matric suction are based on experience. They do not have clear physical meaning and theoretical support. For example, Sillers and Fredlund and Sillers et al. $[42,43]$ think that the matric suction corresponding to the residual water content is $3000 \mathrm{kPa}$. They also think that the residual state is the state that pore water in soil changes from capillary action to adsorption force. This definition is quite popular at present. Based on the recommendations of Sillers and Fredlund and Sillers et al. [42, 43], this paper assumes that the residual matric suction is $3000 \mathrm{kPa}$ for fitting, as shown in the curve of the end of measured value to point $\mathrm{C}$ in Figure 4. Obviously, the volume water content corresponding to the matric suction of $3000 \mathrm{kPa}$ is not the residual volume water content. Through repeated fitting calculation, the residual matric suction is finally assumed to be $10000 \mathrm{kPa}$, as shown in the curve to point $\mathrm{D}$ in Figure 4, the fitting effect of this region is better, and the corresponding residual volume water content is $12.4 \%$.

\subsection{Direct Shear Test and Result Analysis}

\subsubsection{Relationship between Shear Strength and Matric} Suction. Table 4 shows the corresponding shear strength values of the conventional direct shear test under different volume water contents and the equal suction direct shear test under different matric suction. Among them, the corresponding matric suction in the data column of the conventional direct shear test is obtained from the matric suction 
TABLE 4: The corresponding shear strength values of the conventional direct shear test and the equal suction direct shear test.

\begin{tabular}{|c|c|c|c|c|c|c|}
\hline \multicolumn{4}{|c|}{ Conventional direct shear test } & \multicolumn{3}{|c|}{ Equal suction direct shear test } \\
\hline $\begin{array}{l}\text { Volume water } \\
\text { content } / \%\end{array}$ & $\begin{array}{c}\text { Matric } \\
\text { suction } / \mathrm{kPa}\end{array}$ & $\begin{array}{c}\text { Vertical } \\
\text { stress/kPa }\end{array}$ & $\begin{array}{c}\text { Shear } \\
\text { strength } / \mathrm{kPa}\end{array}$ & $\begin{array}{c}\text { Matric } \\
\text { suction } / \mathrm{kPa}\end{array}$ & $\begin{array}{c}\text { Net vertical } \\
\text { stress/kPa }\end{array}$ & $\begin{array}{c}\text { Shear } \\
\text { strength/kPa }\end{array}$ \\
\hline \multirow{3}{*}{44.9} & \multirow{3}{*}{1} & 50 & 36.3 & \multirow{3}{*}{1} & 50 & 36.3 \\
\hline & & 100 & 54.8 & & 100 & 54.8 \\
\hline & & 200 & 91.8 & & 200 & 91.8 \\
\hline \multirow{3}{*}{43.3} & \multirow{3}{*}{25} & 50 & 39.9 & \multirow{3}{*}{25} & 50 & 43.3 \\
\hline & & 100 & 58.2 & & 100 & 62.4 \\
\hline & & 200 & 94.8 & & 200 & 100.6 \\
\hline \multirow{3}{*}{41.8} & \multirow{3}{*}{38} & 50 & 42.4 & \multirow{3}{*}{ l } & 1 & 1 \\
\hline & & 100 & 61.2 & & l & l \\
\hline & & 200 & 98.5 & & 1 & 1 \\
\hline \multirow{3}{*}{40.4} & \multirow{3}{*}{50} & 50 & 55.6 & \multirow{3}{*}{50} & 50 & 57.0 \\
\hline & & 100 & 75.1 & & 100 & 77.6 \\
\hline & & 200 & 114.1 & & 200 & 118.8 \\
\hline \multirow{3}{*}{37.4} & \multirow{3}{*}{75} & 50 & 64.2 & \multirow{3}{*}{1} & 1 & I \\
\hline & & 100 & 84.3 & & I & 1 \\
\hline & & 200 & 124.5 & & 1 & 1 \\
\hline \multirow{3}{*}{34.8} & \multirow{3}{*}{100} & 50 & 72.3 & \multirow{3}{*}{100} & 50 & 69.8 \\
\hline & & 100 & 92.5 & & 100 & 91.5 \\
\hline & & 200 & 132.9 & & 200 & 134.7 \\
\hline \multirow{3}{*}{30.8} & \multirow{3}{*}{150} & 50 & 76.3 & \multirow{3}{*}{150} & 50 & 80.3 \\
\hline & & 100 & 97.2 & & 100 & 102.6 \\
\hline & & 200 & 139.4 & & 200 & 147.4 \\
\hline \multirow{3}{*}{28.8} & \multirow{3}{*}{200} & 50 & 81.3 & \multirow{3}{*}{200} & 50 & 84.5 \\
\hline & & 100 & 102.4 & & 100 & 109.1 \\
\hline & & 200 & 144.7 & & 200 & 154.2 \\
\hline \multirow{3}{*}{24.4} & \multirow{3}{*}{300} & 50 & 87.4 & & 50 & 93.7 \\
\hline & & 100 & 109.2 & 300 & 100 & 116.9 \\
\hline & & 200 & 152.7 & & 200 & 163.3 \\
\hline & & 50 & 92.5 & & 50 & 99.3 \\
\hline 22.3 & 400 & 100 & 114.5 & 400 & 100 & 122.3 \\
\hline & & 200 & 158.6 & & 200 & 168.3 \\
\hline & & 50 & 96.8 & & 50 & 103.5 \\
\hline 20.9 & 500 & 100 & 119.5 & 500 & 100 & 127.1 \\
\hline & & 200 & 164.8 & & 200 & 174.1 \\
\hline
\end{tabular}

corresponding to the volume water content in the soil-water characteristic curve.

The corresponding shear strengths of the conventional direct shear test and equal suction direct shear test under different matric suction are shown in the same figure, as shown in Figure 5. It can be seen from the figure that the shear strength of unsaturated silty clay samples changes with matric suction at different vertical normal stresses, and the change trend of boundary effect zone and transition zone is basically consistent with the soil water characteristic curve. In the boundary effect zone $(0 \sim 38 \mathrm{kPa})$, a small matric suction can still slightly increase the shear strength of the soil, when the matric suction is less than the air-entry value comparing to the fully saturated state. The soil is in an unsaturated state, in the transition zone $(38 \sim 500 \mathrm{kPa})$. The shear strength changes in two stages with the change of the matric suction. When the matric suction increases from $38 \mathrm{kPa}$ to $200 \mathrm{kPa}$, the shear strength increases rapidly and the corresponding volume water content at this stage is $41.8 \% \sim 28 \%$, and the lower limit volume water content is close to that of plastic limit. The increase rate of shear strength gradually decreases after the matric suction exceeds $200 \mathrm{kPa}$. Combining with the soil-water characteristic curve, it can be found that the transition zone can also be divided into two stages, 


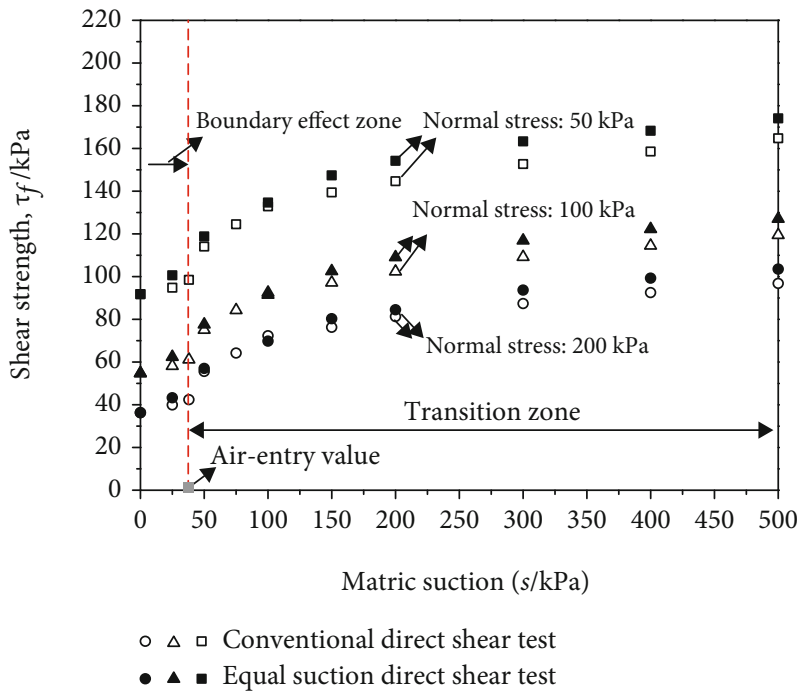

FIgURE 5: The relationship between shear strength and matric suction.

namely, the main transition zone and the secondary transition zone. Taking the matric suction as $200 \mathrm{kPa}$ as the demarcation point, the shear strength in the main transition zone increases rapidly with the matric suction comparing with the secondary transition zone. This is similar to the results of Çokça and Tilgen [44], Bai and Liu [45], Pandya et al. [13], and Khalili et al. [22].

It can be found that the shear strength change trends measured by the two methods are relatively consistent comparing the two test results. When the matric suction is less than the air-entry value, the shear strength of the equal suction direct shear test is basically equal to that of the conventional direct shear test. When the matric suction is in the transition zone, the shear strength of equal suction direct shear test is generally higher than that of conventional direct shear test. Due to the limited range of the matric suction force applied by this test instrument, the results of the matric suction force exceeding $500 \mathrm{kPa}$ cannot be compared.

3.2.2. Relationship between Shear Strength and Matric Suction. In order to avoid the limitation of Bishop equation, Sillers et al. [43] used two independent stress state variables to study the mechanical properties of unsaturated soils. Through a lot of laboratory tests and theoretical analysis, the theoretical formula of the shear strength of unsaturated soils with net normal stress and matric suction as two variables:

$$
\tau_{f}=c^{\prime}+\left(\sigma-u_{a}\right) \tan \varphi^{\prime}+\left(u_{a}-u_{w}\right) \tan \varphi^{b},
$$

where $\varphi^{b}$ represents the rate at which the shear strength increases with the matric suction $\left(u_{a}-u_{w}\right)$, which is simply referred to as the internal friction angle of adsorption. If $c^{\prime}+\left(u_{a}-u_{w}\right) \tan \varphi^{b}$ is replaced by $c$ in the formula (1), the shear strength formula of unsaturated soil can be rewritten as formula (2):

$$
\tau_{f}=c+\left(\sigma-u_{a}\right) \tan \varphi^{\prime},
$$

where $c=c^{\prime}+\left(u_{a}-u_{w}\right) \tan \varphi^{b}$, in which $c$ is the intercept of total cohesion, which is referred to as total cohesion in this article. The total cohesive force $c$ of unsaturated soil is composed of the cohesive force $c^{\prime}$ in the saturated state and the shear strength $\left(u_{a}-u_{w}\right) \tan \varphi^{b}$ caused by the matric suction in the unsaturated state.

Based on the above formula, the total cohesion and effective internal friction angle of soil samples at different volume water contents are obtained according to the results of conventional direct shear tests. By transforming the soil-water characteristic curve into the corresponding matric suction, the relationship between total cohesion and effective internal friction angle with matric suction can be obtained. The strength index of the equal suction direct shear test is obtained by applying the corresponding shear strength of different matric suction. Through calculation, the corresponding shear strength parameters of the conventional direct shear test and equal suction direct shear test under different volume water content and matrix suction are shown in Table 5. Among them, the corresponding matric suction in the data column of the conventional direct shear test is obtained from the matric suction corresponding to the volume water content in the soil-water characteristic curve.

Figures 6 and 7 show the relationship between the total cohesive and effective internal friction angle with the matric suction of equal suction direct shear test and conventional direct shear test. It can be seen from the figures that the total cohesion and effective internal friction angle have different rules of change with the matric suction. With the increase of matric suction, the total cohesion increases nonlinearly and tends to be stable gradually, and its characteristics are synchronous with the shear strength. The effective internal friction angle increases slightly with the increase of the matric suction, and the size is close to the internal friction angle when the soil is saturated, and its change characteristics are not synchronized with the shear strength. According to the geotechnical engineering investigation report of Shaoxing area, the typical silty clay in Shaoxing area is marine sedimentary soil, and the particles are in thin sheet shape. The particles are connected by edge to edge and edge to surface, and the arrangement is directional, with the characteristics of flocculent structure. It contains plant debris, a small amount of flaky particles filled in the coarse particles, clay minerals, silt particles, and humus which adsorb by each other. But microscopically, there is still a very small amount of gas present in the tiny corners of individual pores, the resulting very low suction force plays a role in connecting soil particles, and the lubrication of water between the soil particles is reduced. Therefore, compared with the fully saturated state, the total cohesion and effective internal friction angle of the soil are slightly increased. In the transition zone, the soil is in unsaturated state, the air entering the pores increases gradually, the moisture in the pores 
TABLE 5: Shear strength parameters corresponding to conventional direct shear test and equal suction direct shear test.

\begin{tabular}{|c|c|c|c|c|c|c|c|c|c|c|c|c|}
\hline \multirow{4}{*}{ Conventional direct shear test } & Volume water content $/ \%$ & 44.9 & 43.3 & 41.8 & 40.4 & 37.4 & 34.8 & 30.8 & 28.8 & 24.4 & 22.3 & 20.9 \\
\hline & Matric suction/kPa & 1 & 25 & 38 & 50 & 75 & 100 & 150 & 200 & 300 & 400 & 500 \\
\hline & Total cohesion $/ \mathrm{kPa}$ & 17.8 & 21.6 & 23.7 & 36.1 & 44.1 & 52.1 & 55.3 & 60.2 & 65.7 & 70.4 & 74.1 \\
\hline & Effective internal friction angle $/^{\circ}$ & 20.3 & 20.1 & 20.5 & 21.3 & 21.9 & 22 & 22.8 & 22.9 & 23.5 & 23.8 & 24.4 \\
\hline \multirow{3}{*}{ Equal suction direct shear test } & Matric suction $/ \mathrm{kPa}$ & 1 & 25 & l & 50 & l & 100 & 150 & 200 & 300 & 400 & 500 \\
\hline & Total cohesion $/ \mathrm{kPa}$ & 17.8 & 23.4 & l & 35.5 & l & 47.4 & 57.1 & 63.1 & 69.6 & 75.5 & 79.2 \\
\hline & Effective internal friction angle $/^{\circ}$ & 20.3 & 20.9 & l & 22.4 & l & 23.4 & 24.1 & 24.3 & 24.9 & 24.7 & 25.2 \\
\hline
\end{tabular}

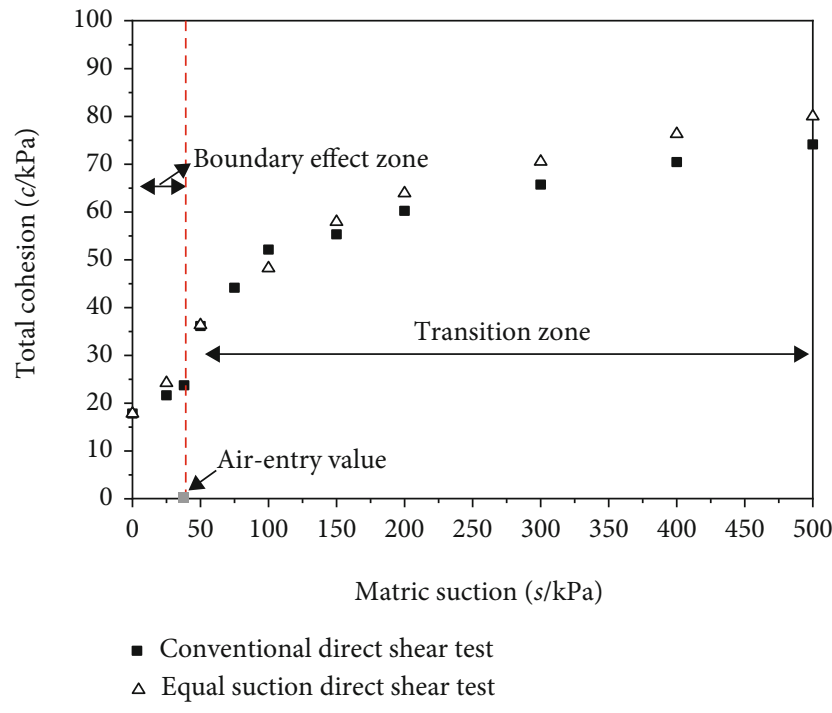

FIGURE 6: Relationship between total cohesion and the matric suction.

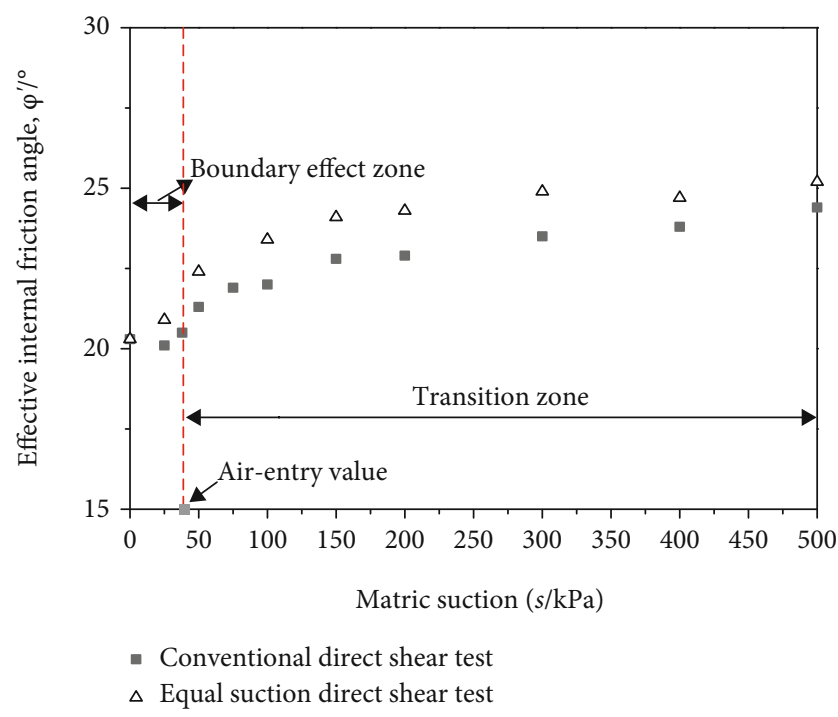

Figure 7: Relationship between the effective internal friction angle and the matric suction.

decreases correspondingly, the matric suction generated by the difference of pore pressure and water pressure increases, and with the change of air-water interface shrinkage membrane, the surface tension generated increases gradually with the increase of air in the pore, so the total cohesion of soil increases. At the same time, as the pore gas entering the soil increases, the moisture gradually decreases, and the lubrication between soil particles is reduced due to moisture, so the effective internal friction angle of the soil increases slightly. However, when the matric suction increased to a certain extent, the water content in the soil would not be discharged any more, and the water content in the soil would remain unchanged, eventually making the total cohesion in the soil gradually stabilized.

By comparing the data points obtained from the two tests, it can be found that in the boundary region $(s \leq 38 \mathrm{kPa})$, the total cohesion and effective internal friction angle under the equal suction direct shear test and the conventional direct shear test have little change, which is basically the same as that under the saturated state. In the transition zone $(38 \mathrm{kPa} \leq S \leq 500 \mathrm{kPa})$, when the matric suction force is lower than $100 \mathrm{kPa}$, the total cohesion measured by the equal suction direct shear test is smaller than the total cohesion measured by the conventional direct shear test, and when the suction direct shear test exceeds $100 \mathrm{kPa}$, the total cohesion is greater than that measured by the conventional direct shear test. However, the effective internal friction angle measured by the equal suction direct shear test is always greater than the effective internal friction angle measured by the conventional direct shear test.

From the above analysis, it can be concluded that with the increase of matric suction, the shear strength and total cohesion of the soil increase significantly, and the effective internal friction angle changes less. It can be considered that the contribution of matric suction to the shear strength is more reflected in the increase in total cohesion.

\section{Prediction Model and Improved Model of Shear Strength Based on Soil-Water Characteristic Curve}

According to the above analysis, as the matric suction increases, the effective internal friction angle of the soil changes only slightly, while the cohesive force changes significantly, so the change of the effective internal friction angle is ignored. In order to consider only the contribution of matric suction to shear strength, the effect of net vertical normal stress on shear strength should be excluded. Therefore, if the net vertical normal stress is 0 , the increment of cohesion 


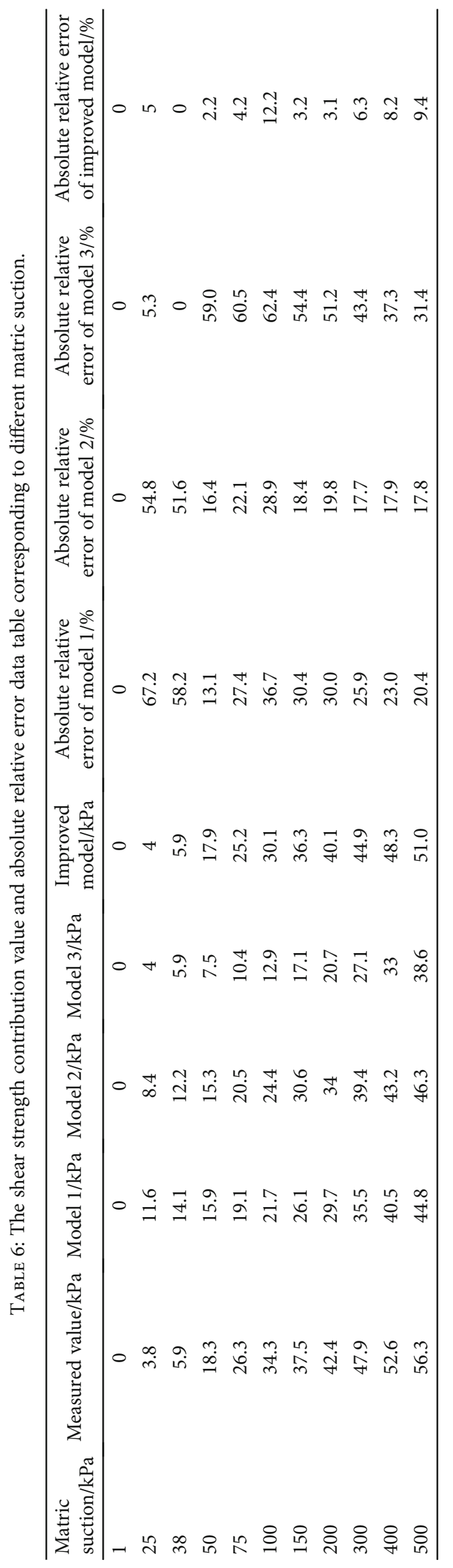




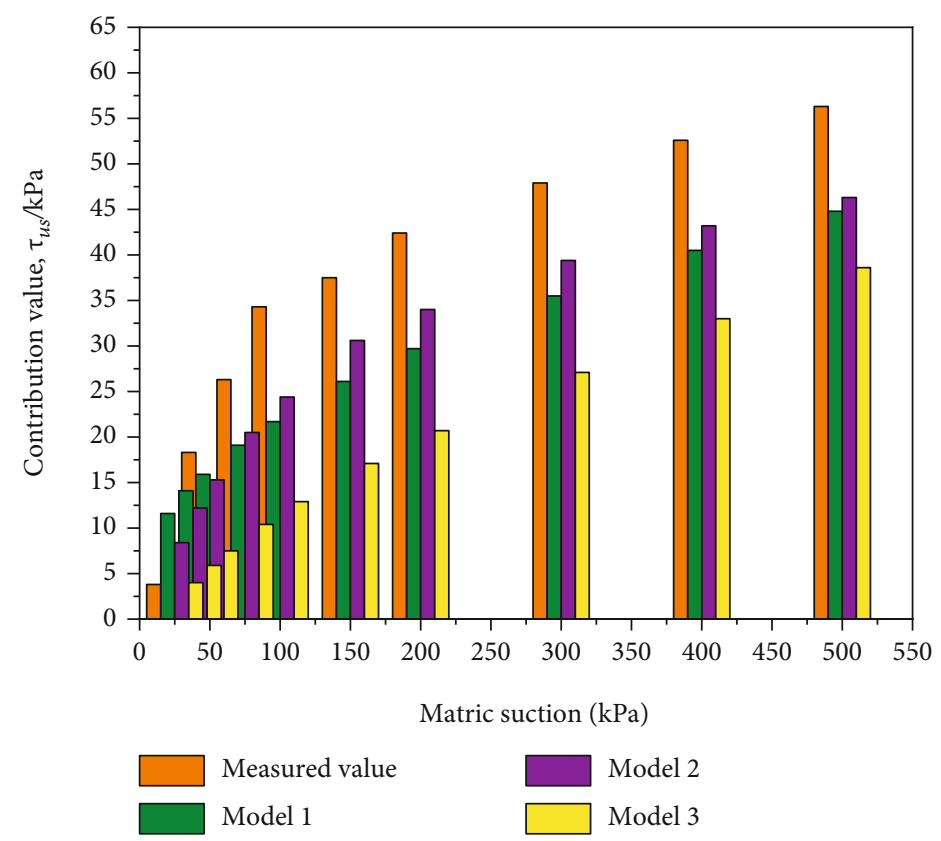

FIGURE 8: Comparison of calculated and measured values of the three models.

obtained from saturated state to unsaturated state is the contribution value of matric suction to shear strength. Based on the research of unsaturated soils, Khalili and Khabbaz [46], Vanapalli et al. [31], Lamborn [47], and others earlier proposed different prediction models for the shear strength of unsaturated soils, which have wide applicability. Without considering the influence of the net vertical normal stress and only considering the contribution of the matric suction to the shear strength, three models of the contribution of the shear strength can be obtained, namely, model 1, model 2 , and model 3, as (4) (6):

$$
\begin{aligned}
& \tau_{u s}=\left(u_{a}-u_{w}\right)^{0.45}\left(u_{a}-u_{w}\right)_{b}^{0.55} \tan \varphi^{\prime}, \\
& \tau_{u s}=\left(u_{a}-u_{w}\right)\left(\frac{\theta_{w}-\theta_{r}}{\theta_{s}-\theta_{r}}\right) \tan \varphi^{\prime}, \\
& \tau_{u s}=\left(u_{a}-u_{w}\right) \theta_{w} \tan \varphi^{\prime}
\end{aligned}
$$

where $\tau_{u s}$ is the contribution value of the matric suction to the shear strength.

According to the results of the direct shear test, the measured shear strength contribution value can be obtained. The internal friction angle $\varphi^{\prime}=20.3^{\circ}$ at saturated state of soil and the soil-water characteristic curve parameters $\left(u_{a}-u_{w}\right)_{b}=$ $38 \mathrm{kPa}, \theta_{s}=44.89 \%$, and $\theta_{r}=12.4 \%$ fitted by VG model are substituted into equations $(4) \sim(6)$ to calculate the contribution value of shear strength under model $1 \sim \operatorname{model} 3$, as shown in Table 6. According to the results in Table 6, the calculated shear strength contribution values of the three models are compared with the measured values, as shown in Figure 8. It can be clearly seen from the bar graph that the shear strength contribution value calculated by model 1 , model 2, and model 3 differs greatly from the measured value and is significantly lower than the measured value. The error analysis of the three models is performed, and the calculation results are shown in Table 6 . The relationship between the absolute relative error of the three models and the change of the matric suction is represented by a bar graph, as shown in Figure 9. It can be seen from Figure 9 that the absolute value of the relative error calculated by the three models has a large dispersion. The absolute relative error calculated by model 1 and model 2 reached the maximum in the boundary area, $67.2 \%$ and $54.8 \%$, respectively, while the absolute relative error calculated by model 3 is close to 0 in the boundary area, and the fitting effect is good. However, in the transition region, the absolute values of relative errors calculated by model 1 and model 2 are mostly in the range of $20 \% \sim 35 \%$, while those of model 3 are mostly in the range of $35 \% \sim 60 \%$. The average errors of the three models are $33.2 \%, 26.5 \%$, and $40.5 \%$. Due to the large error, the three calculation models cannot be directly used in the transition zone to calculate the contribution of the matric suction to the shear strength, and a new improved model needs to be established.

According to the literature [48], taking the matric suction value corresponding to the air-entry value and the residual volume water content as the dividing line, the soil can be divided into the boundary zone, the transition zone, and the unsaturated residual zone. According to the comparison of the absolute relative error calculated by the above model 1 to model 3 , in the boundary zone, that is, the matric suction is less than the air-entry value, only the absolute relative error of model 3 is about $5 \%$, which is in line with the actual allowable error range. Therefore, taking the air-entry value of the soil $38 \mathrm{kPa}$ as the dividing line and based on the formula proposed by Lamborn [47], when the matric suction is less than the air intake value, the relationship between the matric suction and the shear strength contribution value is formula (6); when the matric suction is greater than $38 \mathrm{kPa}$, as the matric 


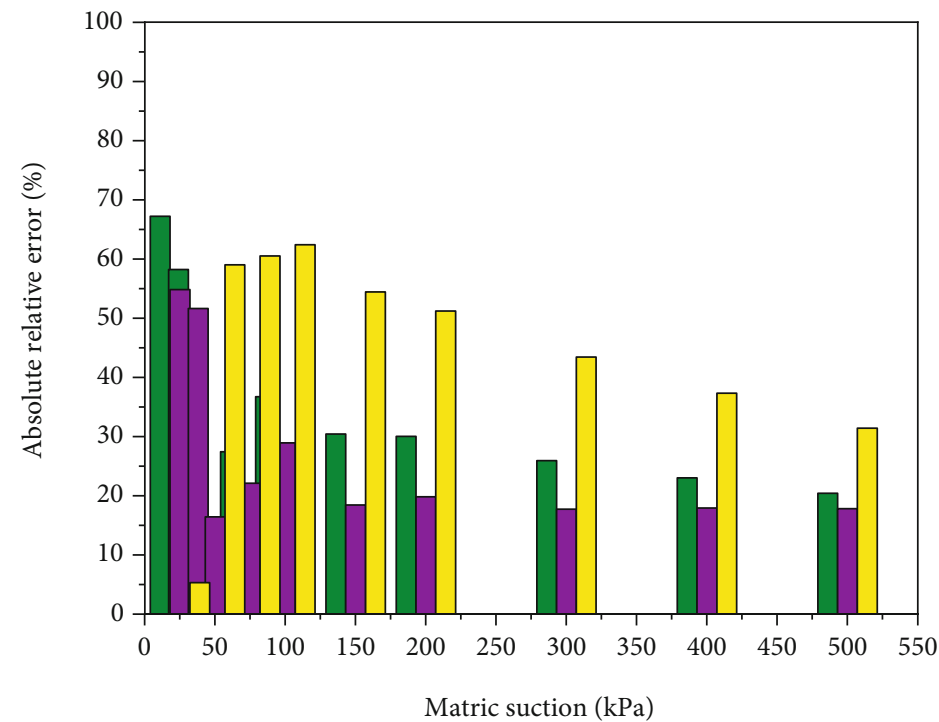

Model 1

Model 2

Model 3

FIGURE 9: The variation of absolute relative error of the three models with matric suction.

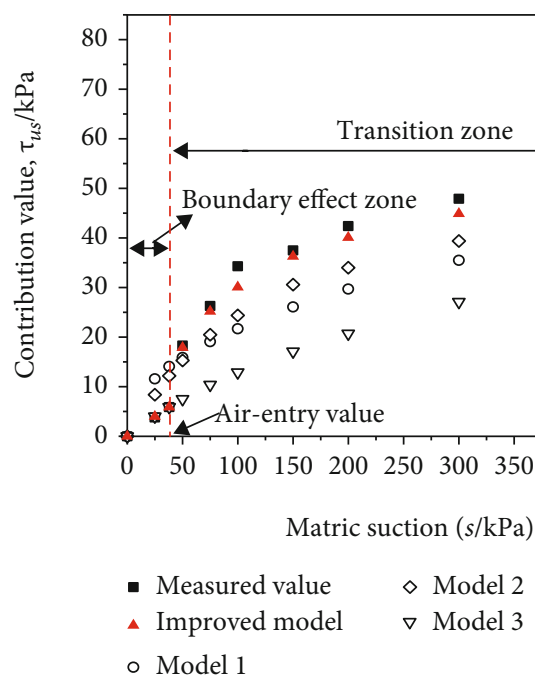

FIGURE 10: Comparison of the shear strength contribution values of the improved model and the three models with the measured values.

suction continues to increase, the contribution rate of the matric suction to the shear strength gradually decreases. Therefore, $38 \mathrm{kPa}$ is used as the initial zero point, and the subsequent matric suction minus $38 \mathrm{kPa}$ is used as the matric suction increase. According to the conversion relationship between matric suction and volume water content in reference [31], the expression of the contribution of matric suction to shear strength can be given as follows:

$$
\tau_{u s}=\frac{\left(u_{a}-u_{w}\right) \tan \varphi^{\prime}}{\left[1+\alpha\left(\left(u_{a}-u_{w}\right)-\left(u_{a}-u_{w}\right)_{b}\right)^{n}\right]^{m}} .
$$

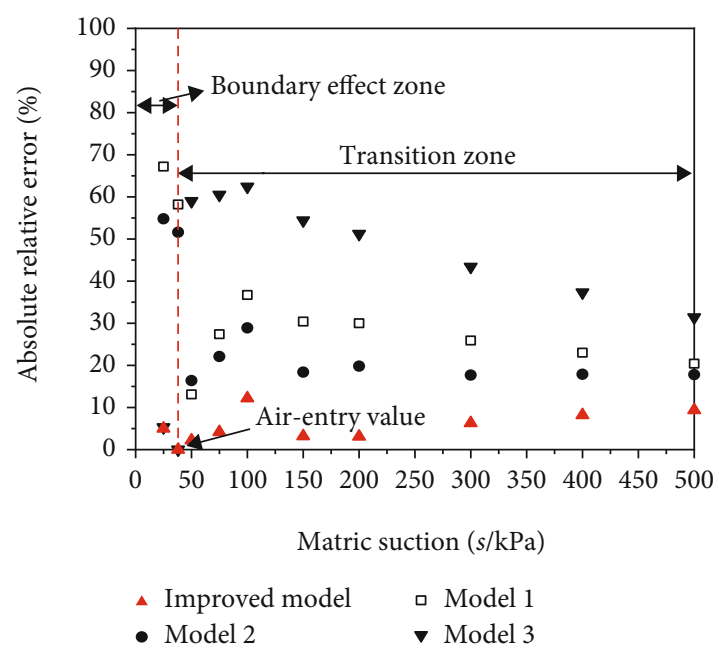

FIgURE 11: Comparison of absolute relative error between the improved model and the three models with the change of matric suction.

Combining equations (6) and (7), the calculation model of the contribution value of matric suction to shear strength can be obtained as follows:

$\tau_{u s}=\left\{\begin{array}{l}\left(u_{a}-u_{w}\right) \theta_{w} \tan \varphi^{\prime},\left(u_{a}-u_{w}\right)<\left(u_{a}-u_{w}\right)_{b}, \\ \frac{\left(u_{a}-u_{w}\right) \tan \varphi^{\prime}}{\left[1+\alpha\left(\left(u_{a}-u_{w}\right)-\left(u_{a}-u_{w}\right)_{b}\right)^{n}\right]^{m}},\left(u_{a}-u_{w}\right) \geq\left(u_{a}-u_{w}\right)_{b} .\end{array}\right.$

According to the foregoing, substituting $\varphi^{\prime}=20.3^{\circ}$, $\left(u_{a}-u_{w}\right)_{b}=38 \mathrm{kPa}, \alpha=0.0 .0122, n=1.733$, and $m=0.423$ 
into improved model (8), the shear strength under different matric suction can be obtained contribution value and compare with the measured value and predicted values of three models, as shown in Figure 10. The relationship between the absolute value of the relative error of model 1, model 2, model 3, and the improved model and matric suction is shown in Figure 11. It can be seen from the figure that, except for the absolute relative error between the actual measured value and the calculated value of the improved model, which exceeds $10 \%$, the absolute relative error of the remaining mea- sured value and the calculated value of the model is within $10 \%$. The average absolute value of relative error of the improved model is $5.4 \%$ through calculation within the range of matric suction measured. Compared with the absolute value of relative error of model 1 to model 3, the mean value of absolute value of relative error obtained by the improved model decreases by $27.8 \%, 21.1 \%$, and $35.1 \%$, respectively, which shows the effectiveness of the improved model.

Therefore, the improved model formula for the shear strength of Shaoxing unsaturated silty clay is as follows:

$$
\tau_{f}=\left\{\begin{array}{l}
c^{\prime}+\left(\sigma-u_{a}\right) \tan \varphi^{\prime}+\left(u_{a}-u_{w}\right) \theta_{w} \tan \varphi^{\prime},\left(u_{a}-u_{w}\right)<\left(u_{a}-u_{w}\right)_{b}, \\
c^{\prime}+\left(\sigma-u_{a}\right) \tan \varphi^{\prime}+\frac{\left(u_{a}-u_{w}\right) \tan \varphi^{\prime}}{\left[1+\alpha\left(\left(u_{a}-u_{w}\right)-\left(u_{a}-u_{w}\right)_{b}\right)^{n}\right]^{m}},\left(u_{a}-u_{w}\right) \geq\left(u_{a}-u_{w}\right)_{b} .
\end{array}\right.
$$

\section{Conclusions}

(1) The soil water characteristic curve fitted by VG model combined with the strength measured by conventional direct shear test is in good agreement with that measured by equal suction direct shear test of unsaturated soil. Within a certain range, the shear strength and total cohesive force of the soil increase nonlinearly with the increase of matric suction, which has similar phase characteristics of the soilwater characteristic curve, and the effective internal friction angle changes little

(2) By analyzing the physical meaning of the air-entry value and taking the air-entry value as the demarcation point, an improved model of the shear strength of unsaturated silty clay in this paper is proposed. The absolute value of the error between the shear strength contribution value calculated by the improved model and the measured value is basically within $10 \%$. Compared with the average absolute relative error of model 1 to model 3 , the absolute relative error of the improved model decreases by $27.8 \%$, $21.1 \%$, and $35.1 \%$, respectively, which shows the effectiveness of the improve model

The research in this paper can simplify the testing method of unsaturated soil shear strength, save time, and provide new ideas for the popularization and application of unsaturated soil shear strength theory in engineering practice.

\section{Data Availability}

The data used to support the findings of this study are available from the corresponding author upon request.

\section{Conflicts of Interest}

The authors declare no conflicts of interest.

\section{Acknowledgments}

This research was funded by the Zhejiang Provincial Natural Science Foundation of China (Grant number Q20E080042) and the Scientific research project of Zhejiang education department (Grant number Y201839206).

\section{References}

[1] S. Jeong, K. Lee, J. Kim, and Y. Kim, "Analysis of rainfallinduced landslide on unsaturated soil slopes," Sustainability, vol. 9, no. 7, pp. 1280-1299, 2017.

[2] J. Kim, S. Jeong, and R. A. Regueiro, "Instability of partially saturated soil slopes due to alteration of rainfall pattern," Engineering Geology, vol. 147, pp. 28-36, 2012.

[3] L. Ciabatta, S. Camici, L. Brocca et al., "Assessing the impact of climate-change scenarios on landslide occurrence in Umbria Region," Journal of Hydrology, vol. 541, no. A, pp. 285-295, 2016.

[4] H. Rahardjo, A. Satyanaga, E. C. Leong, and Y. S. Ng, "Effects of groundwater table position and soil properties on stability of slope during rainfall," Journal Geotechnical and Geoenvironmental, vol. 136, no. 11, pp. 1555-1564, 2010.

[5] B. S. Par, H. Cho, and S. P. Youn, "Analysis and evaluation of stability for the reactivated landslide along deep-seated weakness zones," International Journal of Industrial Engineering: Theory, Applications, and Practice, vol. 7, no. 3, p. 2016, 2016.

[6] H. Rahardjo, Y. Kim, N. Gofar, E. C. Leong, C. L. Wang, and J. L. H. Wong, "Field instrumentations and monitoring of GeoBarrier System for steep slope protection," Transportation Geotechnics, vol. 16, pp. 29-42, 2018.

[7] H. Rahardjo, T. T. Lim, M. F. Chang, and D. G. Fredlund, "Shear strength characteristics of a residual soil in Singapore," Canadian Geotechnical Journal, vol. 32, pp. 60-77, 1995.

[8] Y. Liu, F. H. Lee, S. T. Quek, E. J. Chen, and J. T. Yi, "Effect of spatial variation of strength and modulus on the lateral compression response of cement-admixed clay slab," Géotechnique, vol. 65, no. 10, pp. 851-865, 2015.

[9] Y. Liu, L. Q. He, Y. J. Jiang, M. M. Sun, E. J. Chen, and F. H. Lee, "Effect of in-situ water content variation on the spatial 
variation of strength of deep cement-mixed clay," Géotechnique, vol. 69, no. 5, pp. 391-405, 2019.

[10] N. Li, Y. Zhu, F. Zhang, S. M. Lim, W. Wu, and W. Wang, "Unconfined compressive properties of fiber-stabilized coastal cement clay subjected to freeze-thaw cycles," International Journal of Engineering Science, vol. 9, no. 143, pp. 356-363, 2021.

[11] W. Wang, J. Li, and J. Hu, "Unconfined mechanical properties of nanoclay cement compound modified calcareous sand of the South China Sea," Advances in Civil Engineering, vol. 2020, Article ID 6623710, 16 pages, 2020.

[12] W. Wang, Y. Li, and K. Yao, "Strength properties of nano$\mathrm{MgO}$ and cement stabilized coastal silty clay subjected to sulfuric acid attack," Marine Georesources \& Geotechnology, vol. 38, no. 10, pp. 1177-1186, 2020.

[13] S. Pandya, A. Sachan, S. Pandya, and A. Sachan, "Variation of collapse potential and stiffness degradation with matric suction of compacted unsaturated cohesive soil," International Journal of Industrial Engineering: Theory, Applications, and Practice, vol. 28, no. 7, pp. 1329-1337, 2017.

[14] Q. Zhai, H. Rahardjo, A. Satyanaga, and G. Dai, "Estimation of unsaturated shear strength from soil-water characteristic curve," Acta Geotechnica, vol. 3, no. 5, pp. 253-269, 2019.

[15] A. M. Elsharief and O. A. Abdulaziz, "Effects of matric suction on the shear strength of highly plastic compacted, Innovative Geotechnics for Africa-Bouassida," Khemakhem \& Haffoudhi (Eds.), vol. 63, no. 58, pp. 97-103, 2015.

[16] F. Champiré, A. Fabbri, J. C. Morel, H. Wong, and F. McGregor, "Impact of relative humidity on the mechanical behavior of compacted earth as a building material," Construction and Building Materials, vol. 1, no. 27, pp. 77-78, 2016.

[17] R. Schnellmann, H. Rahardjo, and H. R. Schneider, "Unsaturated shear strength of a silty sand," Engineering Geology, vol. 162, no. 23, pp. 88-96, 2013.

[18] S. Nam, M. Gutierrez, P. Diplas, and J. Petrie, "Determination of the shear strength of unsaturated soils using the multistage direct shear test," Engineering Geology, vol. 122, no. 3-4, pp. 272-280, 2011.

[19] G. Idinger and W. Wei, "Shear Strength of Granular Soil Under Saturated and Unsaturated Conditions," Recent Advances in Geotechnical Research, Springer Series in Geomechanics and Geoengineering, vol. 7, no. 7, pp. 79-89, 2019.

[20] A. M. Rasool and J. Kuwano, "Role of matric suction on shear strength of unsaturated compacted soil at low confining stress. Proceedings of GeoShanghai 2018 International Conference," Multi-Physics Processes in Soil Mechanics and Advances in Geotechnical Testing, vol. 13, no. 23, pp. 120-128, 2018.

[21] H. Pujiastuti, A. Rifa'i, A. D. Adi, and T. F. Fathani, "The effect of matric suction on the shear strength of unsaturated sandy clay," International Journal of Geomate, vol. 14, no. 42, pp. 112-119, 2018.

[22] N. Khalili, A. Russell, A. Khoshghalb, S. Frydman, and R. Baker, "Matrix Suction and Shear Strength of Unsaturated Clay," in Unsaturated Soils: Research \& Applications, CRC Press, 2014.

[23] C. Erdal and P. Hüseyin Tilgen, "Shear strength-suction relationship of compacted Ankara clay," Applied Clay Science, vol. 49, pp. 400-404, 2010.

[24] J. Kim, W. Hwang, and Y. Kim, "Y. Kim (2018), "Effects of hysteresis on hydro-mechanical behavior of unsaturated soil"," Engineering Geology, vol. 245, pp. 1-9, 2018.
[25] A. Ahmed, M. Sahadat Hossain, M. S. Khan, K. Greenwood, and A. Shishani, "Moisture var-iation in expansive subgrade through field instrumentation and geophysical testing," Engineering Geology, vol. 1, pp. 45-58, 2018.

[26] Q. Zhai and H. Rahardjo, "H. Rahardjo (2015), "Estimation of permeability function from the soil-water characteristic curve"," Engineering Geology, vol. 199, pp. 148-156, 2015.

[27] S. W. Tyler and S. W. Wheatcraft, "Fractal process in soil water retention," Water Resources Research, vol. 26, no. 5, pp. 10471054, 1990.

[28] M. Feng and D. G. Fredlund, "Hysteretic influence associated with thermal conductivity sensor measurements," in Proceedings from Theory to the Practice of Unsaturated Soil Mechanics in Association with the 52nd Canadian Geotechnical Conference and Unsaturated Soil Group, pp. 651-657, Regina Sask, 1999.

[29] M. T. Van Genuchten, "A close-form equation for predicting the hydraulic conductivity of unsaturated soils," Soil Science Society of America Journal, vol. 44, no. 56, pp. 892-898, 1980.

[30] D. G. Fredlund and A. Xing, "Equations for the soil-water characteristic curve," Canadian Geotechnical Journal, vol. 31, no. 4, pp. 521-532, 1994.

[31] S. K. Vanapalli, D. G. Fredlund, D. E. Pufahl, and A. W. Clifton, "Model for the prediction of shear strength with respect of soil suction," Canadian Geotechnical Journal, vol. 33, no. 3, pp. 379-392, 1996.

[32] A. L. Oberg and G. Sallfors, "Determination of shear strength parameters of unsaturated silts and based on the water retention curve," Geotechnical Testing Journal, vol. 20, no. 1, pp. 40-48, 1997.

[33] C. Tang, R. Borden, and M. Gabr, "A simplified direct shear testing procedure to evaluate unsaturated shear strength," Geotechnical Testing Journal, vol. 41, no. 2, pp. 223-234, 2018.

[34] Ministry of Construction of the People's Republic of China, General Administration of quality supervision, inspection and Quarantine of the people's Republic of China, Engineering Classification Standard of Soil GB/T50145-2007, China Planning Press, Beijing, 2008.

[35] Ministry of Water Resources of the People's Republic of China, Standards for Geotechnical Test Methods GB/T50123-2019[S], China Planning Press, Beijing, 2019.

[36] Ministry of Transport of the People's Republic of China, Technical Code for Construction of Highway Subgrade JTG/T 36102019 [S], People's Communications Press, Beijing, 2019.

[37] E. J. Macari, R. Laureano, and J. Hoyos, "Mechanical behavior of an unsaturated soil under multi-axial stress states," Geotechnical Testing Journal., vol. 24, no. 1, pp. 14-22, 2001.

[38] J. D. Mendes and G. Toll, "Influence of initial water content on the mechanical behavior of unsaturated sandy clay soil," International Journal of Geomechanics, vol. 16, no. 6, pp. D4016005-1-D401600518, 2016.

[39] M. Rosone, C. A. Farulla, and A. Ferrari, "Shear strength of a compacted scaly clay in variable saturation conditions," Acta Geotechnica, vol. 11, no. 1, pp. 37-50, 2016.

[40] W. R. Gardner, "Some steady-state solutions of the moisture flow equations with application to evaporation from a water table," Soil Science, vol. 85, no. 4, pp. 228-232, 1958.

[41] H. Brooks and A. T. Corey, Conference of Hydraulic Properties of Porous Media, Colorado State University. Hydrol. Paper, 1964. 
[42] W. S. Sillers and D. G. Fredlund, "Statistical assessment of soil-water characteristic curve models for geotechnical engineering," Canadian Geotechnical Journal, vol. 38, no. 6, pp. 1297-1313, 2001.

[43] W. S. Sillers, D. G. Fredlund, and N. Zakerzadeh, Mathematical Attributes of Some Soil-Water Characteristic Curve Models, Springer, Netherlands, 2001.

[44] E. Çokça and H. Tilgen, "Shear strength-suction relationship of compacted Ankara clay," Applied Clay Science, vol. 49, no. 4, pp. 400-404, 2010.

[45] F. Q. Bai and S. H. Liu, "Measurements of the shear strength of an expansive soil by combining a filter paper method and direct shear tests," Geotechnical Testing Journal, vol. 35, no. 3, pp. 451-459, 2013.

[46] N. Khallili and M. H. Khabbaz, "A unique relationship for $\chi$ for the determination of the shear strength of unsaturated soils," Geotechnique, vol. 48, no. 5, pp. 681-687, 1998.

[47] M. J. Lamborn, A Micromechanical Approach to Modeling Partly Saturated Soils, Texas A \& M University, College Station, 1986.

[48] D. G. Fredlund and H. Rahardjo, Soil Mechanics for Unsaturated Soils, China Architecture and Building Press, Beijing, 1997. 